\title{
2,4-Dioxo-1,3-diazaspiro[4,5]decane-3-sulfonic Acid as a Novel Solid Phase Halogen-free Acid Catalyst: Preparation, Characterization and Evaluation
}

\author{
Behzad Khalili* ${ }^{*}$, Aref Atashrazm and Mona Rasoulian \\ Department of Chemistry, Faculty of Sciences, University of Guilan, P.O. Box 41335-1914, Rasht, Iran.
}

Received 28 August 2018, revised 8 June 2019, accepted 29 July 2019.

\begin{abstract}
N-sulfonated cyclohexylhydantoin (NSCH), a new $\mathrm{N}$-sulfonic acid compound, was prepared and characterized using FT-IR, ${ }^{1} \mathrm{H}$ NMR, ${ }^{13}$ C NMR, UV-Vis and TGA analysis. The potential catalyst efficiency was examined, using synthesis of chromene, xanthene and hydroquinoline derivatives under solvent-free conditions. All of the examined model reactions gave excellent yields, and required short reaction times. Simple catalyst preparation and work-up under mild reaction condition, with low cost and the ability to recover the catalyst for reuse without significant loss of activity are some of the notable advantages of the introduced catalyst.
\end{abstract}

KEYWORDS

Hydantoin, N-sulfonated acidic catalyst, chromene, xanthene, hydroquinoline.

\section{Introduction}

Common Brønsted acid hydrogen containing catalysts such as sulfuric acid, p-toluene sulfonic acid, hydrochloric acid, hydrofluoric acid and phosphoric acid are used as catalysts to promote many organic synthetic reactions and industrial processes. However, the above-mentioned Brønsted acid catalysts generally result in homogeneous reaction mixtures, causing problems with separation from reaction media, resulting in some disadvantages such as negative environmental impact, wasting energy and increased chemical wastes production. For these reasons, solid acid catalysts have received considerable attention to replace such conventional homogeneous Brønsted acid catalysts, and have shown higher efficiency, operational simplicity, easy reusability, recoverability, non-corrosiveness and higher environmental acceptance. ${ }^{1-5}$ Therefore, the development of solid acid catalysts could be very helpful for altering technologies using homogeneous acid catalysts. One of the simplest ways to access solid acidic materials is making use of nitrogencontaining organic compounds and introducing $\mathrm{SO}_{3} \mathrm{H}$ and $\mathrm{HSO}_{4}$ groups as Bronsetd acid functions into their chemical structure, which make them water soluble and enhance their polarity, which aids their use under solvent-free conditions. Many of such solid acid catalysts have been reported. ${ }^{6-10}$

Imidazolidine-2,4-diones (or hydantoins) are well known substructures found in a wide range of biologically active drugs and natural products. ${ }^{11}$ From the synthetic point of view, hydantoins could be useful precursors for preparation of acidic catalysts because their acidic N-H could be replaced by the sulfonic acid functional group. Accordingly, sulfonic acid-functionalized hydantoin is now examined as a potential solid acid catalyst in the multicomponent synthesis of xanthenes, chromenes and hydroquinolines. ${ }^{12-14}$

Xanthene, chromene and hydroquinoline derivatives are important organic compounds with a wide range of applicability and biological activity. ${ }^{15-20}$ Although some synthetic methodologies have been reported for each class of these compounds in the literature, ${ }^{21-32}$ each with their own advantages, many of them ${ }^{*}$ To whom correspondence should be addressed. E-mail: b.khalili@guilan.ac.ir suffer from some disadvantages. The use of homogeneous acid catalysts may result in some difficulties with product separation and purification, low yield, long reaction time, use of toxic organic solvents and harsh reaction procedures. Therefore, we have developed a new and efficient catalyst to overcome these problems.

\section{Experimental}

2.1. General Procedure for the Synthesis of

Cyclohexylhydantoin ( $\mathrm{CHH})$

Cyclohexanone $(5 \mathrm{mmol}, 0.52 \mathrm{~mL}$ ) and ammonium carbonate (10 mmol, $1 \mathrm{~g}$ ) were added to $30 \mathrm{~mL} \mathrm{1:1} \mathrm{ethanol/water.} \mathrm{The}$ mixture was heated at $60-70{ }^{\circ} \mathrm{C}$ until all of the ammonium carbonate dissolved. Then, a solution of potassium cyanide $(10 \mathrm{mmol}, 0.7 \mathrm{~g})$ in $10 \mathrm{~mL}$ of distilled water was added dropwise over $10 \mathrm{~min}$. After $48 \mathrm{~h}$ at $60-70^{\circ} \mathrm{C}$, the mixture was kept at room temperature for $45 \mathrm{~min}$, and then below $0^{\circ} \mathrm{C}$ for $2 \mathrm{~h}$. The precipitate was filtered and recrystallized from ethanol. Finally, the desired hydantoin was obtained as needles (70\%), mp 220$222{ }^{\circ} \mathrm{C}^{33}$

\subsection{General Procedure for the Synthesis of}

Cyclohexylhydantoin- N-sulfonic Acid (NSCH)

A mixture of cyclohexylhydantoin $(2 \mathrm{mmol}, 0.2 \mathrm{~g})$ and dichloromethane $(10 \mathrm{~mL})$ was stirred at $0{ }^{\circ} \mathrm{C}$ for $2 \mathrm{~h}$, generating a uniform white paste. Then chlorosulfonic acid $(2 \mathrm{mmol}, 0.25 \mathrm{~mL})$ in dichloromethane $(2 \mathrm{~mL}$ ) was added over a period of $10 \mathrm{~min}$ at $0^{\circ} \mathrm{C}$. The resulting clear solution was kept at $0^{\circ} \mathrm{C}$ for $2 \mathrm{~h}$ and then allowed to reach room temperature and stirred for a further $2 \mathrm{~h}$. After evaporation of the dichloromethane, the residue was washed with diethyl ether $(3 \times 5 \mathrm{~mL})$. The final precipitate was obtained (95\%), $\mathrm{mp} 198^{\circ} \mathrm{C}$.

\subsection{General Procedure for the Synthesis of Chromenes}

To a mixture of dimedone $(1 \mathrm{mmol})$, the benzaldehyde (1 mmol) and malonitrile $(1.2 \mathrm{mmol})$ was added the NSCH catalyst $(15 \mathrm{mg})$ and the mixture was stirred at $80^{\circ} \mathrm{C}$ for the appropri- 
ate time. The reaction progress was monitored by TLC. After completion of the reaction, chloroform $(10 \mathrm{~mL})$ was used to extract the catalyst, and the residual product was recrystallized from ethanol.

\subsection{General Procedure for the Synthesis of Xanthenes}

A mixture of,dimedone $(2 \mathrm{mmol})$, the benzaldehyde $(1 \mathrm{mmol})$. And the NSCH catalyst $(15 \mathrm{mg})$ was stirred at $80^{\circ} \mathrm{C}$ for a given time. At the end of the reaction (monitored by TLC), the reaction mixture was cooled to room temperature. The catalyst was separated from the reaction mixture by addition of chloroform $(10 \mathrm{~mL})$, then the crude residue was recrystallized from ethanol.

\subsection{General Procedure for the Synthesis of Hydroquinolines}

A stirred mixture of dimedone $(1 \mathrm{mmol})$, benzaldehyde ( $1 \mathrm{mmol})$, ethyl acetoacetate $(1 \mathrm{mmol})$, ammonium acetate ( $2 \mathrm{mmol}$ ) and the NSHH catalyst $\left(15 \mathrm{mg}\right.$ ) was heated at $80^{\circ} \mathrm{C}$ and kept for a given time, and the reaction was monitored by TLC. The reaction mixture was cooled to room temperature and the catalyst separated from the reaction mixtures by addition of chloroform $(10 \mathrm{~mL})$. The crude product was recrystallized from ethanol.

\subsection{Optimizing Reaction Conditions for Tetrahydrochromene} Synthesis

A mixture of dimedone ( $1 \mathrm{mmol})$, benzaldehyde $(1 \mathrm{mmol})$ and malononitrile $(1 \mathrm{mmol})$ was reacted in the presence of different amounts of $\mathrm{NSCH}$ in the temperature range $25-120{ }^{\circ} \mathrm{C}$ in the absence and presence of different solvents. The results are shown in Fig. 4a.

\subsection{Determination of the Acid Content of the Catalyst}

The $0.04 \mathrm{M}$ catalyst solution $(20 \mathrm{~mL})$ was titrated with the $0.05 \mathrm{M}$ sodium hydroxide solution. The titration curve is given in

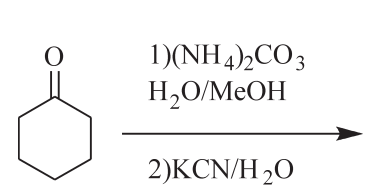<smiles>O=C1NC(=O)C2(CCCCC2)N1</smiles>

$\mathrm{CH}$

$\mathrm{CHH}$
Fig. 3. As seen in Fig. 3, the titration reached the end point when $18 \mathrm{~mL}$ of the titrant was added to the catalyst solution. This amount of the titrant is nearly same as that $(16 \mathrm{~mL})$ which is needed to complete neutralization of the $20 \mathrm{~mL}$ of the $0.04 \mathrm{M}$ solution of the catalyst according to the calculations below (Equation 1). These results showed that the catalyst contains one acidic proton, verifying its sulfonated $\mathrm{NH}$ group.

$$
\begin{aligned}
& \mathrm{M}_{1} \mathrm{~V}_{1 \text { (acid) }}=\mathrm{M}_{2} \mathrm{~V}_{2 \text { (base) }} \\
& 0.04(\mathrm{M}) \times 20(\mathrm{~mL})=0.05(\mathrm{M}) \times \mathrm{V}_{2} \\
& \mathrm{~V}_{2}=16 \mathrm{~mL}
\end{aligned}
$$

\section{Results and Discussion}

\subsection{Catalyst Characterization}

The structure of the cyclohexylhydantoin-N-sulfonic acid catalyst, which was synthesized as shown in Fig. 1, was characterized by FT-IR, ${ }^{1} \mathrm{H}$ NMR, ${ }^{13} \mathrm{C}$ NMR, TGA, DTG, and UV-Vis analysis.

The corresponding FT-IR spectra of cyclohexylhydantoin and cyclohexylhydantoin-N-sulfonicacid are shown in Fig. SI1 (Fig. 1 in supporting information). In the case of cyclohexylhydantoin$\mathrm{N}$-sulfonic acid, the $\mathrm{OH}$ stretching band of the $\mathrm{SO}_{3} \mathrm{H}$ functional group appeared as broad bands between 3200 and $3700 \mathrm{~cm}^{-1}$, centred at $3414 \mathrm{~cm}^{-1}$. Characteristic absorption bands related to the $\mathrm{SO}_{2}$ asymmetric and symmetric, $\mathrm{S}-\mathrm{N}$ symmetric and $\mathrm{S}-\mathrm{OH}$ bending vibrations of appeared at 1262,1176, 1069 and $879 \mathrm{~cm}^{-1}$. $^{10}$

Thermogravimetric analysis of $\mathrm{CHH}$ and $\mathrm{NSCH}$ was carried out to investigate their structural stability during thermal changes. Fig. 2 displays a typical DTGA spectrum for $\mathrm{CHH}$ and NSCH. CHH shows a two-step thermal decomposition at $100{ }^{\circ} \mathrm{C}$ and $290{ }^{\circ} \mathrm{C}$ which corresponds to the loss of the moisture and complete decomposition of the $\mathrm{CHH}$ structure, respectively. In the case of NSCH, a three-step thermal decomposition appeared

Figure 1 Synthesis of NSCH.<smiles>O=C1NC2(CCCCC2)C(=O)N1S(=O)(=O)O</smiles>

$\mathrm{NSCH}$

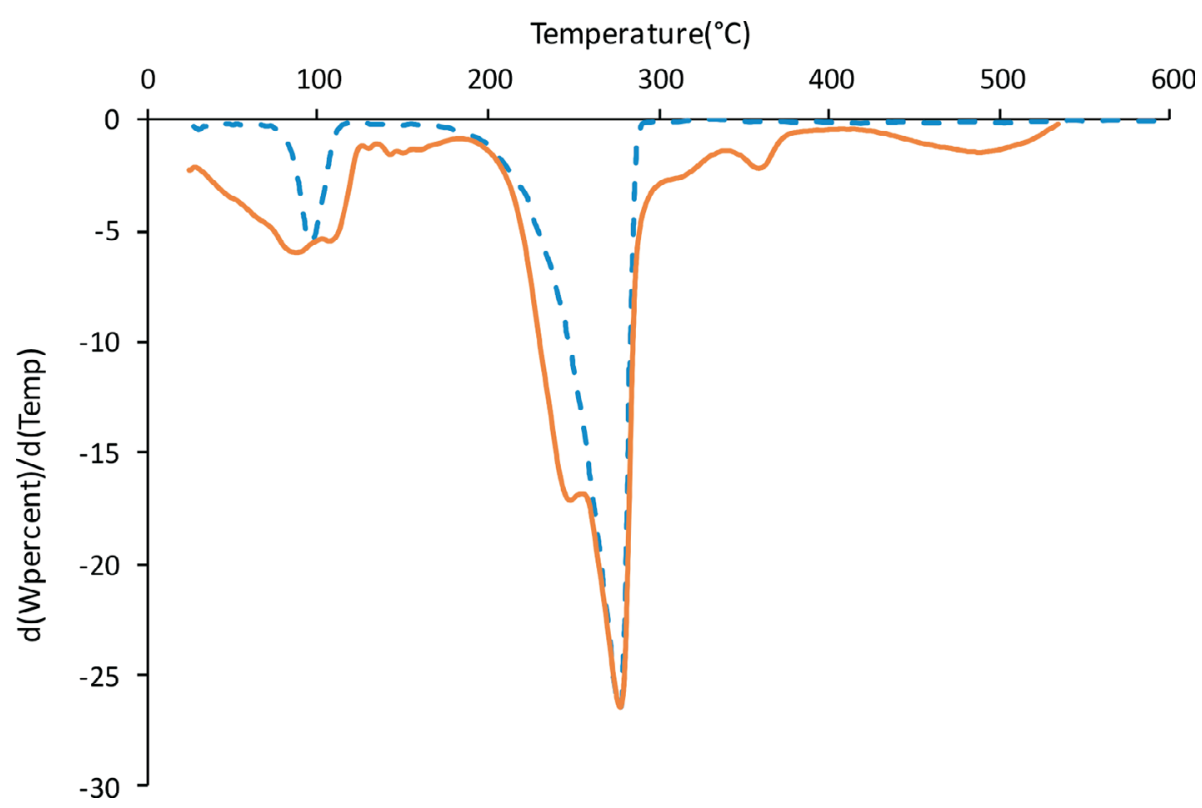

Figure 2 DTGA curves for $\mathrm{CHH}(--)$ and $\mathrm{NSCH}(-)$. 


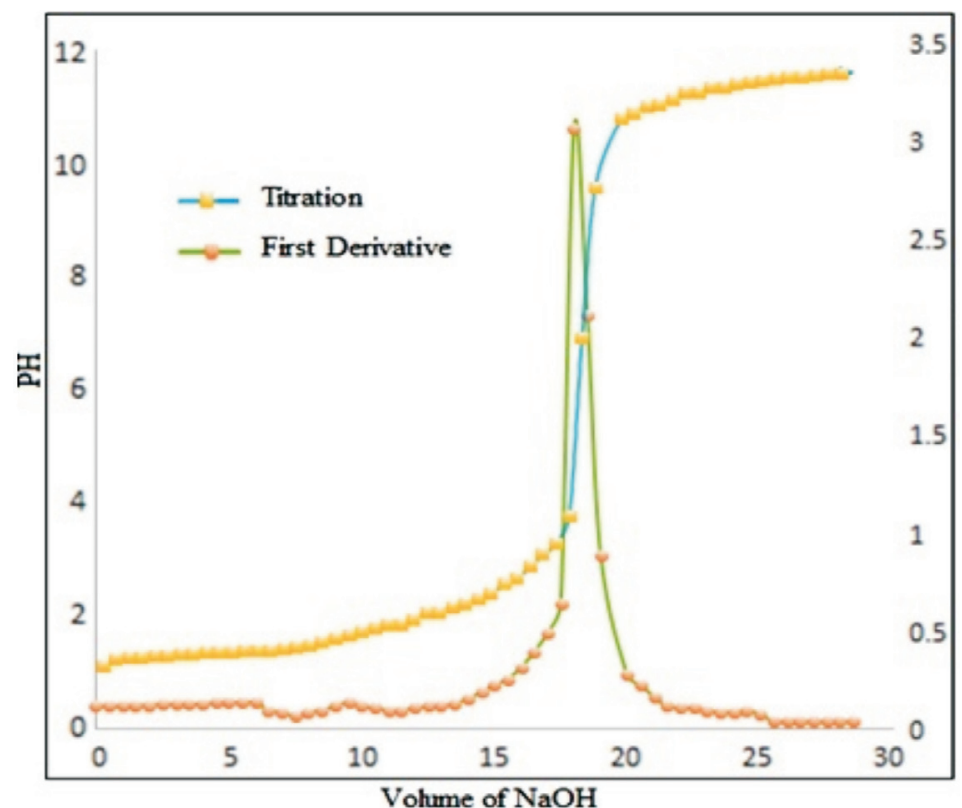

Figure 3 Titration and its first derivative curves of NSCH.

which includes firstly, weight loss in the range $30-120^{\circ} \mathrm{C}$, due to the removal of the local moisture. Secondly, the thermal decomposition of the sulfonic group appeared at $240^{\circ} \mathrm{C}$ as a weight loss. The third decomposition, at $290{ }^{\circ} \mathrm{C}$, corresponds to the complete decomposition of the NSCH. According to the DTGA results, the $\mathrm{NSCH}$ catalyst is thermally stable up to $240{ }^{\circ} \mathrm{C}$.

${ }^{1} \mathrm{H}$ NMR spectra of $\mathrm{CHH}$ and NSCH from 7ppm to 12ppm are shown in (Fig. SI2). The ${ }^{1} \mathrm{H}$ NMR spectrum of $\mathrm{CHH}$ displayed two singlet peaks at 10.54 and $8.38 \mathrm{ppm}$ due to the hydrogens attached to the nitrogen atoms. After functionalization of $\mathrm{CHH}$ with chlorosulfonic acid, the $\mathrm{NH}$ peak at 10.54 was replaced by a new peak at $11.45 \mathrm{ppm}$, which corresponds to the newly attached $\mathrm{SO}_{3} \mathrm{H}$ proton. In addition, the ${ }^{13} \mathrm{C}$ NMR spectra of NSCH showed six peaks verifying its chemical structure.

\subsection{Catalyst Acidity Power}

One way to evaluate the acidic power of an acid in organic media is the use of the Hammett method (see equation below), using the UV-Vis technique. ${ }^{7}$

$$
\mathrm{H}_{0}=\mathrm{pK}(\mathrm{I})_{\mathrm{aq}}+\log \left([\mathrm{I}]_{\mathrm{s}} /\left[\mathrm{IH}^{+}\right]_{\mathrm{s}}\right)
$$

In this equation $\mathrm{pK}(\mathrm{I})_{\mathrm{aq}}$ represents the $\mathrm{pKa}$ value of an indicator in aqueous solution. The concentration of the indicator in protonated and deprotonated forms are represented as $\left[\mathrm{IH}^{+}\right]_{\mathrm{s}}$ and $[\mathrm{I}]_{\mathrm{S}^{\prime}}$, respectively. The values of $[\mathrm{I}]_{\mathrm{S}} /\left[\mathrm{IH}^{+}\right]_{\mathrm{s}}$ were easily obtained using the UV-Visible spectrum according to the Lambert-Beer's Law. In this study, the indicator and organic solvent are 4-nitroaniline $\left(\mathrm{pK}(\mathrm{I})_{\mathrm{aq}}=0.99\right)$ and $\mathrm{CCl}_{4}$.

In the absence of the catalyst the mixture of the 4-nitroaniline and organic solvent shows the maximum absorbance at $330 \mathrm{~nm}$ with an intensity of $\left(A_{\max }=2.2228\right)$, while as the catalyst was added to this mixture the intensity of the maximum absorbance at $330 \mathrm{~nm}$ decreased to $\left(\mathrm{A}_{\max }=2.2616\right)$. The decrease in the absorbance intensity of the indicator is due to the fact that some of the indicator molecules are protonated by the acidic protons which are supplied by the catalyst molecules, and the concentration of the non-protonated forms of the indicator molecules which are responsible for the absorption at $330 \mathrm{~nm}$ decreased. Table 1 lists the data obtained for the evaluation of the acidity power of the catalyst using Hammett acidity function.
Table 1 Calculation of the Hammett acidity function $\left(\mathrm{H}_{\mathrm{o}}\right)$ for NSSH.

\begin{tabular}{cccccc}
\hline Entry & Catalyst & $\mathrm{A}_{\max }$ & {$[\mathrm{I}]_{\mathrm{S}} \%$} & {$\left[\mathrm{IH}^{+}\right]_{\mathrm{S}} / \%$} & $\mathrm{H}_{\mathrm{o}}$ \\
\hline 1 & - & 2.2228 & 100 & 0 & - \\
2 & $\mathrm{NSSH}$ & 1.2616 & 56.76 & 43.24 & 1.108 \\
\hline
\end{tabular}

Experiment conditions: 4-nitroaniline $[\mathrm{pK}(\mathrm{I}) \mathrm{aq}=0.99], 1.44 \times 10^{-4} \mathrm{~mol} \mathrm{~L}^{-1}(10 \mathrm{~mL})$, NSSH $(10 \mathrm{mg}), 25^{\circ} \mathrm{C}$.

\subsection{Evaluation of the Catalytic Activity}

After the characterization of NSCH, its catalytic activity was examined using it as solid acid catalyst to promote a number of synthetic organic reactions such as synthesis of the tetrahydrochromenes (Fig. 4a), xanthenes (Fig. 4b) and hydroquinolines (Fig. 4c).

The results showed that the optimum amount of the $\mathrm{NMCH}$ was $6 \mathrm{~mol} \%$, and by using this amount of the catalyst the reaction proceeded best under solvent-free conditions at $80{ }^{\circ} \mathrm{C}$. In the absence of the catalyst, the reaction was incomplete, even after $24 \mathrm{~h}$.

The yield of products from different benzaldehydes, under different reaction conditions, is shown in Table 2. The presence of electron-donating substituents in the benzaldehyde, e.g. entry 5 in Table 2 required longer reaction times.

The proposed mechanism for tetrahydrochromene synthesis in the presence of NSCH is shown in Fig. SI3a.

Similarly, entries 13-17 report the optimized yields for the synthesis of 3,3,6,6-tetramethyl-1, 8-dioxooctahydroxanthenes from benzaldehyde derivatives $(1 \mathrm{mmol})$ and dimedone $(2 \mathrm{mmol})$ in presence of $\mathrm{NSCH}$ at $80^{\circ} \mathrm{C}$ under solvent-free condition (Fig. 4b).

The synthesis of the hydroquinoline derivatives (Fig. 4c) was achieved efficiently from the benzaldehyde derivatives $(1 \mathrm{mmol})$, dimedone $(1 \mathrm{mmol})$ and ethyl acetoacetate $(1 \mathrm{mmol})$ in the presence of $\mathrm{NSCH}$ at $80^{\circ} \mathrm{C}$ under solvent-free condition. The results are listed in Table 2 (entries 18-22). Two alternative reaction pathways to achieve this outcome are shown in Fig. SI3c.

\subsection{Reusability of the Catalyst}

Recovery of the catalyst and its reuse were investigated under the optimized reaction procedure for the above three procedures. In each case, the catalyst was filtered off at the end of the 
a<smiles>CC1(C)CC(=O)CC(C)(C)C1</smiles>

b<smiles>CC1(C)CC(=O)CC(=O)C(C)(C)C1=NS(=O)(=O)c1ccccc1</smiles>

c<smiles>CCOC(=O)C1=C(C)NC2=C(C(=O)CC(C)(C)C2)C1c1ccccc1</smiles>

Figure 4 Synthesis of tetrahydrochromenes (a), 1, 8-dioxooctahydroxanthenes (b) and hydroquinolines (c) catalyzed by $\mathrm{NSCH}$ at $80^{\circ} \mathrm{C}$.

Table 2 Synthesis of tetrahydrochromene (entries 1-12), 1, 8-dioxooctahydroxanthenes (entries 13-17) and hydroquinoline (entries 18-22) derivatives catalyzed by $\mathrm{NSCH}$ at $80^{\circ} \mathrm{C}$ under solvent-free condition.

\begin{tabular}{llcccc}
\hline Entry & Aldehyde & Time/min & Yield/\% & Found & Reported [ref] \\
\hline 1 & $4 \mathrm{H}-\mathrm{C}_{6} \mathrm{H}_{5}$ & 15 & 95 & $228-230$ & $227-230[12]$ \\
2 & $4 \mathrm{~F}-\mathrm{C}_{6} \mathrm{H}_{5}$ & 17 & 95 & $210-211$ & $211-214[12]$ \\
3 & $4 \mathrm{Cl}-\mathrm{C}_{6} \mathrm{H}_{5}$ & 17 & 95 & $210-212$ & $209-212[12]$ \\
4 & $4 \mathrm{Br}-\mathrm{C}_{6} \mathrm{H}_{5}$ & 17 & 95 & $195-197$ & $197-200[12]$ \\
5 & $4 \mathrm{OH}-\mathrm{C}_{6} \mathrm{H}_{5}$ & 28 & 94 & $204-206$ & $204-207[12]$ \\
6 & $4 \mathrm{OMe}-\mathrm{C}_{6} \mathrm{H}_{5}$ & 20 & 95 & $210-211$ & $211-214[12]$ \\
7 & $4 \mathrm{NO}_{2}-\mathrm{C}_{6} \mathrm{H}_{5}$ & 17 & 95 & $177-179$ & $175-178[12]$ \\
8 & $4 \mathrm{CN}_{6} \mathrm{C}_{6} \mathrm{H}_{5}$ & 17 & 95 & $223-225$ & $211-214[12]$ \\
9 & $4 \mathrm{Me}-\mathrm{C}_{6} \mathrm{H}_{5}$ & 20 & 95 & $215-217$ & $218-220[12]$ \\
10 & $4 \mathrm{OEt}_{-} \mathrm{C}_{6} \mathrm{H}_{5}$ & 23 & 96 & $223-225$ & $225-227[12]$ \\
11 & $3 \mathrm{NO}_{2}-\mathrm{C}_{6} \mathrm{H}_{5}$ & 17 & 95 & $210-212$ & $210-213[12]$ \\
\hline
\end{tabular}

reaction, washed with ethanol, dried in an oven and reused for the same reaction. This process was repeated three times and no significant changes in the reaction time or yield were observed, verifying the practical recyclability of this catalyst (Fig. 5).

\begin{tabular}{llcccc}
\hline Entry & Aldehyde & Time/min & Yield/\% & Found & Reported [ref] \\
\hline 12 & $2 \mathrm{Cl}-\mathrm{C}_{6} \mathrm{H}_{5}$ & 20 & 93 & $215-217$ & $216-218[12]$ \\
13 & $4 \mathrm{H}-\mathrm{C}_{6} \mathrm{H}_{5}$ & 10 & 95 & $197-198$ & $198-200[9]$ \\
14 & $4 \mathrm{Cl}-\mathrm{C}_{6} \mathrm{H}_{5}$ & 10 & 95 & $230-232$ & $229-231[9]$ \\
15 & $4 \mathrm{Br}-\mathrm{C}_{6} \mathrm{H}_{5}$ & 12 & 94 & $281-283$ & $282-284[9]$ \\
16 & $4 \mathrm{NO}_{2}-\mathrm{C}_{6} \mathrm{H}_{5}$ & 10 & 96 & $220-224$ & $220-222[9]$ \\
17 & $3 \mathrm{Me}-\mathrm{C}_{6} \mathrm{H}_{5}$ & 15 & 92 & $199-202$ & $198-200[9]$ \\
18 & $4 \mathrm{H}-\mathrm{C}_{6} \mathrm{H}_{5}$ & 12 & 97 & $222-224$ & $220-222[7]$ \\
19 & $4 \mathrm{Cl}-\mathrm{C}_{6} \mathrm{H}_{5}$ & 15 & 92 & $242-244$ & $241-243[7]$ \\
20 & $4 \mathrm{Br}-\mathrm{C}_{6} \mathrm{H}_{5}$ & 15 & 94 & $246-248$ & $248-252[7]$ \\
21 & $4 \mathrm{NO}{ }_{2}-\mathrm{C}_{6} \mathrm{H}_{5}$ & 15 & 93 & $241-243$ & $238-240[7]$ \\
22 & $4 \mathrm{Me}-\mathrm{C}_{6} \mathrm{H}_{5}$ & 17 & 92 & $257-260$ & $259-261[7]$ \\
\hline
\end{tabular}

\subsection{Comparison of the Reported Efficiency with Previous} Work

To evaluate the efficiency of our newly introduced procedures, comparison of the our results for the synthesis of chromenes,

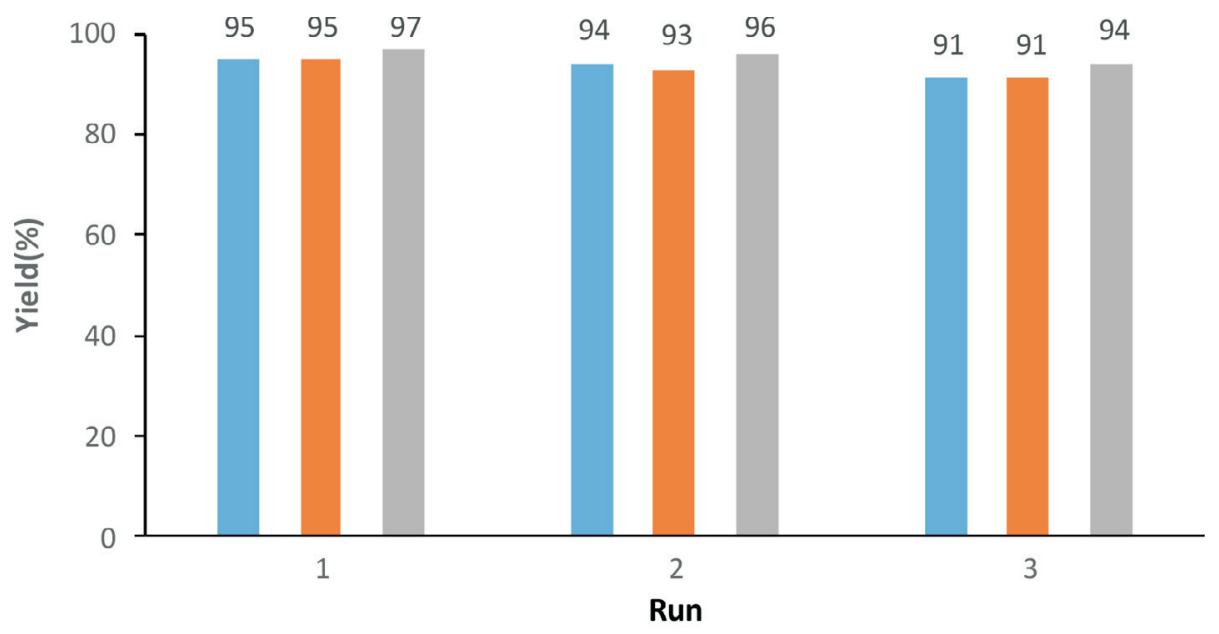

- Reusability of NSCH in synthesis of tetrahyd roxanthenes

- Reusability of NSCH in synthesis of 1,8-dioxooctahyd roxanthenes

- Reusability of NSCH in synthesis of hydroquinoline

Figure 5 Reusability of the NSCH in the synthesis of tetrahydrochromenes, 1, 8-dioxooctahydroxanthenes and hydroquinoline. 
Table 3 Comparison of the results obtained from the synthesis of tetrahydrochromenes, 1, 8-dioxooctahydroxanthenes and hydroquinolines in the presence of $\mathrm{NSCH}$ with those obtained using other catalysts.

\begin{tabular}{|c|c|c|c|c|c|}
\hline \multirow[t]{28}{*}{ Product } & Catalyst(loading) & Reaction condition & Time/min & Yield/\% & [ref] \\
\hline & {$[\mathrm{PVPH}] \mathrm{HSO}_{4}(14 \mathrm{mg})$} & EtOH: $\mathrm{H}_{2} \mathrm{O} / 80^{\circ} \mathrm{C}$ & 10 & 96 & [12] \\
\hline & $\mathrm{PPA}-\mathrm{SiO}_{2}(10 \mathrm{mg})$ & $\mathrm{H}_{2} \mathrm{O}$ & 13 & 80 & [15] \\
\hline & $\mathrm{SiO}_{2}-\mathrm{Pr}-\mathrm{SO}_{3} \mathrm{H}(20 \mathrm{mg})$ & EtOH: $\mathrm{H}_{2} \mathrm{O} /$ reflux & 15 & 97 & [16] \\
\hline & EDDA (90 mg) & Solvent-free/r.t. & 5 & 93 & [21] \\
\hline & SB-DABCO $(6 \mathrm{~mol} \%)$ & $\mathrm{EtOH} / \mathrm{r.t}$ & 35 & 96 & [22] \\
\hline & $\mathrm{NaBr}(6 \mathrm{~mol} \%)$ & Solvent-free $/ 70^{\circ} \mathrm{C}$ & 10 & 95 & [23] \\
\hline & $\mathrm{NSCH}(6 \mathrm{~mol} \%)$ & Solvent-free $/ 80^{\circ} \mathrm{C}$ & 15 & 95 & This work \\
\hline & Silica sulfuric acid (30 mg) & Solvent-free $/ 80{ }^{\circ} \mathrm{C}$ & 60 & 97 & [13] \\
\hline & NSPVPS (20 mg) & Solvent-free $/ 100^{\circ} \mathrm{C}$ & 10 & 98 & [17] \\
\hline & DSIMHS (0.25 mmol) & Solvent-free $/ 55^{\circ} \mathrm{C}$ & 45 & 94 & [18] \\
\hline & $\mathrm{PO}\left(\mathrm{OSO}_{3} \mathrm{H}\right)_{3}(90 \mathrm{mg})$ & Solvent-free $/ 80^{\circ} \mathrm{C}$ & 15 & 84 & [24] \\
\hline & SuSA (10 mg) & Solvent-free $/ 80^{\circ} \mathrm{C}$ & 35 & 92 & [25] \\
\hline & $\mathrm{P}_{2} \mathrm{O}_{5} / \mathrm{SiO}_{2}(12 \mathrm{mg})$ & Solvent-free $/ 80^{\circ} \mathrm{C}$ & 90 & 97 & [26] \\
\hline & MSA (5 mol $\%$ ) & Solvent-free $/ 100^{\circ} \mathrm{C}$ & 60 & 96 & [27] \\
\hline & CAN/HY-zeolite (100 mg) & Solvent-free $/ 80^{\circ} \mathrm{C}$ & 90 & 88 & [28] \\
\hline & Montmorillonite K10 (300 mg) & Solvent-free $/ 100^{\circ} \mathrm{C}$ & 120 & 82 & [29] \\
\hline & $\mathrm{NSCH}(6 \mathrm{~mol} \%)$ & Solvent-free $/ 80^{\circ} \mathrm{C}$ & 15 & 95 & This work \\
\hline & Scolecite (200 mg) & EtOH/reflux & 45 & 93 & [30] \\
\hline & {$[\mathrm{PVPH}] \mathrm{ClO}_{4}(40 \mathrm{mg})$} & Solvent-free $/ 100^{\circ} \mathrm{C}$ & 8 & 97 & [19] \\
\hline & PZM-300 $(0.25 \mathrm{mmol})$ & EtOH/reflux & 40 & 94 & [31] \\
\hline & $\mathrm{Cs}_{2.5} \mathrm{H}_{0.5} \mathrm{PW}_{12} \mathrm{O}_{40}(0.01 \mathrm{mmol})$ & $\mathrm{TBAB} / 110^{\circ} \mathrm{C}$ & 6 & 92 & [32] \\
\hline & $\mathrm{La}_{2} \mathrm{O}_{3}(10 \mathrm{~mol} \%)$ & $\mathrm{TFE} / \mathrm{rt}$ & 60 & 90 & [34] \\
\hline & PS/PTSA (30 mg) & Solvent-free $/ 60^{\circ} \mathrm{C}$ & 15 & 92 & [20] \\
\hline & SBA-Pr-SO ${ }_{3} \mathrm{H}(50 \mathrm{mg})$ & Solvent-free $/ 100^{\circ} \mathrm{C}$ & 10 & 85 & [35] \\
\hline & Catalyst-free & $\mathrm{H}_{2} \mathrm{O} /$ reflux & $8 \mathrm{~h}$ & 96 & [14] \\
\hline & {$[\mathrm{DABCO}]\left(\mathrm{SO}_{3} \mathrm{H}\right)_{2}(\mathrm{Cl})_{2}$} & Solvent-free $/ 100^{\circ} \mathrm{C}$ & 45 & 87 & [36] \\
\hline & $\mathrm{NSCH}(6 \mathrm{~mol} \%)$ & Solvent-free $/ 80^{\circ} \mathrm{C}$ & 12 & 97 & This work \\
\hline
\end{tabular}

xanthenes and hydroquinolines using NSCH as catalyst with the results reported previously in the literature were carried out (Table 3).The newly developed method herein reduced reaction times, excess use of the reagents, especially catalyst amount, and considerably improved on lengthy conditions for catalyst preparation.

\section{Conclusions}

In summary, we have introduced a novel halogen-free solid acid catalyst, N-sulfonated cyclohexylhydantoin (NSCH), which has high acidic power and catalytic activity. The efficiency of the NSCH catalyst was evaluated in the synthesis of tetrahydrochromene, 1,8-dioxooctahydroxanthene and hydroquinoline derivatives. The results clearly showed that the $\mathrm{NSCH}$ catalyst has high catalytic activity to enhance many of the organic synthetic reactions that require acidic conditions. The simple preparation of the catalyst, high availability of the starting materials, recyclability and reusability of the catalyst are advantages of this procedure. The solvent-free conditions, easy work-up and short reaction times are further advantages of the presented procedure.

\section{Acknowledgements}

Partial support of this work from the Research Council of the University of Guilan is gratefully acknowledged. The authors are thankful to the Iran National Science Foundation: INSF, Grant number 95815510, for supporting this work.

\section{Conflict of interest}

The authors declare no conflict of interest.

\section{Supplementary Material}

Supplementary information is provided in the online supplement.

\section{${ }^{5}$ ORCID iD}

B. Khalili:

orcid.org/0000-0002-0001-2824

\section{References}

1 N. Ahmed and Z.N. Siddiqui, Perchloric acid modified-cellulose: a versatile, novel and biodegradable heterogeneous solid acid catalyst for single-pot synthesis of novel bis-pyran annulated heterocyclic scaffolds under solvent-free conditions, J. Mol. Catal. A: Chem., 2014, $387,45-56$.

2 A. Praminik and S. Bhar, Alumina-sulfuric acid catalyzed ecofriendly synthesis of xanthenediones, Catal. Commun., 2012, 20, $17-24$.

3 Z.N. Siddiqui, K. Khan and N. Ahmed, Nano fibrous silica sulphuric acid as an efficient catalyst for the synthesis of $\beta$-enaminone, Catal. Lett., 2014, 144, 623-632.

4 A. Rajack, K. Yuvaraju, Ch. Praveen and Y.L.N. Murthy, A facile synthesis of 3,4-dihydropyrimidinones/thiones and novel $\mathrm{N}$-dihydro pyrimidinone-decahydroacridine-1, 8-diones catalyzed by cellulose sulfuric acid, J. Mol. Catal., 2013, 370, 197-204.

5 M.D. Gonz'alez Y. Cesteros, J. Llorca and P. Salagre, Boosted selectivity toward high glycerol tertiary butyl ethers by microwave-assisted sulfonic acid-functionalization of SBA-15 and beta zeolite, J. Catal., 2012, 290, 202-209.

6 O. Goli-Jolodar, F. Shirini and M. Seddighi, Introduction of O-sulfonated poly (vinylpyrrolidonium) hydrogen sulfate as an efficient, and reusable solid acid catalyst for some solvent-free multicomponent reactions, RSC Adv., 2016, 6, 44794-44806.

7 O. Goli-Jolodar, F. Shirini and M. Seddighi, Introduction of a novel nanosized $\mathrm{N}$-sulfonated Brønsted acidic catalyst for the promotion of the synthesis of polyhydroquinoline derivatives via Hantzsch condensation under solvent-free conditions, RSC Adv., 2016, 6, 26026-26037.

8 K. Mohammadi, F. Shirini and A. Yahyazadeh, 1,3-Disulfonic acid imidazolium hydrogen sulfate: a reusable and efficient ionic liquid for the one-pot multi-component synthesis of pyrimido[4,5-b]quinoline derivatives, RSC Adv., 2015, 5, 23586-23590.

9 F. Shirini, M.P. Najafi, S. Moayedi and M. Seddighi, Introduction of $\mathrm{O}$-sulfonated poly(4-vinylpyrrolidonium) chloride as a polymeric 
and reusable catalyst for the synthesis of xanthene derivatives, RSC Adv., 2014, 4, 38581-38588.

10 F. Shirini, M. Abedini, M. Seddighi, O. Goli-Jelodari, M. Safarpoor, $\mathrm{N}$. Langroodi and S. .Zamani, Introduction of a new bi-SO${ }_{3} \mathrm{H}$ ionic liquid based on 2,2'-bipyridine as a novel catalyst for the synthesis of various xanthene derivatives, RSC Adv., 2014, 4, 63526-63532.

11 a) E. Ware, The chemistry of the hydantoins, Chem. Rev., 1950, 46, 403 476 . b) B. Eftekhari-Sis and M. Zirak, Chemistry of $\alpha$-oxoesters: a powerful tool for the synthesis of heterocycles, Chem. Rev., 2015, 115, 156-264. c) B. Eftekhari-Sis, M. Zirak and A. Akbari, Arylglyoxals in synthesis of heterocyclic compounds, Chem. Rev., 2013, 113, 2958-3043

12 a) F. Shirini, M. Abedini, S. Zarrabzadeh and M. Seddighi, Efficient synthesis of $4 \mathrm{H}$-pyran derivatives using a polymeric catalyst based on PVP, J. Iran. Chem. Soc., 2015, 12, 2105-2113. b) B. Eftekhari-Sis, M. Sarvari Karajabad and S. Haqverdi, Pyridylmethylaminoacetic acid functionalized $\mathrm{Fe}_{3} \mathrm{O}_{4}$ magnetic nanorods as an efficient catalyst for the synthesis of 2-aminochromene and 2-aminopyran derivatives, Sientia Iranica, 2014, 24, 3022-3031.

13 M. Seyyedhamzeh, P. Mirzaei and A. Bazgir, Solvent-free synthesis of aryl-14H-dibenzo [a, j] xanthenes and 1, 8-dioxo-octahydro-xanthenes using silica sulfuric acid as catalyst, Dyes Pigm., 2008, 3, 836-839.

14 B.P. Bandgar, P.E. More and V.T. Kamble, J.V. Totre, Synthesis of polyhydroquinoline derivatives under aqueous media, Arkivoc, 2008, 15, $1-8$.

15 A. Davoodnia, S. Allameh, S. Fazli and N. Tavakoli-Hoseini, One-pot synthesis of 2-amino-3-cyano-4-arylsubstituted tetrahydrobenzo[b]pyranscatalysed by silica gel-supported polyphosphoric acid (PPA-SiO2) as an efficient and reusable catalyst, Chem. Pap., 2., 2011, 65, 714-720.

16 G.M. Ziarani, A. Abbasi, A. Badiei and Z. Aslani, An efficient synthesis of tetrahydrobenzo[b]pyran derivatives using sulfonic acid functionalized silica as an efficient catalyst, J. Chem., 2011, 8, 293-299.

17 F. Shirini, M. Abedini and R. Pourhasan, N-sulfonic acid poly (4-vinylpyridinium) chloride: a novel polymeric and reusable catalyst for the preparation of xanthenes derivatives, Dyes Pigm., 2013, 99, 250-255.

18 F. Shirini, A. Yahyazadeh and K. Mohammadi, One-pot synthesis of various xanthene derivatives using ionic liquid 1,3-disulfonic acid imidazolium hydrogen sulfate as an efficient and reusable catalyst under solvent-free conditions, Chin. Chem. Lett., 2014, 25, 341-347.

19 M. Abedini, F. Shirini and M. Mousapour, Poly(vinylpyrrolidinium) perchlorate as a new and efficient catalyst for the promotion of the synthesis of polyhydroquinoline derivatives via Hantzsch condensation, Res. Chem. Intermed., 2016, 42, 2303-2315.

20 M.V. Reddy and Y.T. Jeong, Polystyrene-supported p-toluenesulfonic acid: a new, highly efficient, and recyclable catalyst for the synthesis of hydropyridine derivatives under solvent-free conditions, Synlett., 2012, 23, 2985-2991.

21 Z. Zhou, Y. Zhang and X. Hu, Efficient one-pot synthesis of tetrahydrobenzo[b]pyrans by ethylenediamine diacetate-catalyzed multicomponent reaction under solvent-free conditions, Polycyclic Aromat. Compd., 2017, 37, 39-45.
22 A. Hasaninejad, M. Shekouhy, N. Golzar, A. Zare and M.M. Doroodmand, Silica bonded n-propyl-4-aza-1-azoniabicyclo[2.2.2] octane chloride (SB-DABCO): a highly efficient, reusable and new heterogeneous catalyst for the synthesis of $4 \mathrm{H}$-benzo[b]pyran derivatives, Appl. Catal. A: General, 2011, 402, 11-22.

23 I. Devi and P.J. Bhuyan, Sodium bromide catalysed one-pot synthesis of tetrahydrobenzo[b]pyrans via a three-component cyclocondensation under microwave irradiation and solvent free conditions, Tetrahedron Lett., 2004, 45, 8625-8627.

24 S. Rezayati, Z. Erfani and R. Hajinasiri, Phospho sulfonic acid as efficient heterogeneous Brønsted acidic catalyst for one-pot synthesis of $14 \mathrm{H}$-dibenzo[a,j]xanthenes and 1, 8-dioxo-octahydro-xanthenes, Chem. Pap., 2015, 69, 536-543.

25 F. Shirini and N.G. Khaligh, Succinimide-N-sulfonic acid: an efficient catalyst for the synthesis of xanthene derivatives under solvent-free conditions, Dyes Pigm., 2012, 95, 789-794.

26 Hasaninejad, A. Silica-supported phosphorus-containing catalysts efficiently promoted synthesis of 1,8 -dioxo-octahydro-xanthenes under solvent-free conditions, Chem. Sci. Trans. 1, 2012, 2, 233-238.

27 B. Karami, Z. Zare and K. Eskandari, Molybdate sulfonic acid: preparation, characterization, and application as an effective and reusable catalyst for octahydroxanthene-1, 8-dione synthesis, Chem. Pap., 2013, $67,145-154$

28 P. Sivaguru and A. Lalitha, Ceric ammonium nitrate supported HY-zeolite: an efficient catalyst for the synthesis of 1, 8-dioxo-octahydroxanthenes, Chin. Chem. Lett., 2014, 25, 321-323.

29 M. Dabiri, S. Azimi and A. Bazgir, One-pot synthesis of xanthene derivatives under solvent-free conditions, Chem. Pap., 2008, 62, 522 526.

30 L.S. Gadekar, S.S. Katkar, S.R. Mane, B.R. Arbad, M.K. Lande, Scolecite catalyzed facile and efficient synthesis of polyhydroquinoline derivatives through Hantzsch multi-component condensation, Bull. Korean Chem. Soc., 2009, 30, 2532-2534.

$31 \mathrm{M}$. Abdollahi-Alibeik and S.S. Hoseinikhah, $\mathrm{ClO}_{4}^{-} / \mathrm{Zr}-\mathrm{MCM}-41$ nanoparticles prepared at mild conditions: a novel solid acid catalyst for the synthesis of polyhydroquinolines, J. Iran. Chem. Soc., 2016, 13, 1339-1347.

32 H. Khabazzadeh, E.T. Kermani, D. Afzali, A. Amiri and A. Jalaladini, Efficient one-pot synthesis of polyhydroquinoline derivatives using $\mathrm{Cs}_{25} \mathrm{H}_{0.5} \mathrm{PW}_{12} \mathrm{O}_{40}$ as a heterogeneous and reusable catalyst in molten salt media, Arab. J. Chem., 2012, 5, 167-172.

33 N.O. Mahmoodi and Z. Khodaee, Evaluating the one-pot synthesis of hydantoins, Arkivoc, 2007, 3, 29-36.

34 S.U. Tekale, V.P. Pagore, S.S. Kauthale and R P. Pawar, $\mathrm{La}_{2} \mathrm{O}_{3} / \mathrm{TFE}$ : an efficient system for room temperature synthesis of Hantzsch polyhydroquinolines, Chin. Chem. Lett., 2014, 25,1149-1152.

35 G. Mohammadi Ziarani, A.R. Badiei, Y. Khaniania and M. Haddadpour, One pot synthesis of polyhydroquinolines catalyzed by sulfonic acid functionalized SBA-15 as a new nanoporous acid catalyst under solvent free conditions, Iran. J. Chem. Chem. Eng., 2010, 29, 1-10.

36 F. Nemati and S.G. Alizadeh, Bi-SO3H Functionalized ionic liquid based on DABCO: new and efficient catalyst for facile synthesis of dihydropyrimidinones, J. Chem., 2013, 1, 2013-2017. 


\section{Supplementary material to:}

B. Khalili, A. Atashrazm and M. Rasoulian,

2,4-Dioxo-1,3-diazaspiro[4,5]decane-3-sulfonic Acid as a Novel Solid Phase Halogen-free Acid Catalyst: Preparation, Characterization and Evaluation,

S. Afr. J. Chem., 2019, 72, 195-200. 


\title{
Supporting Information
}

for

2,4-dioxo-1,3-diazaspiro[4,5]decane-3-sulfonic acid as a novel solid phase halogen free acid catalyst: preparation, characterization and evaluation

\author{
Behzad khalili*, Aref Atashrazm and Mona Rasoulian \\ *Corresponding author's E-mail: b.khalili@guilan.ac.ir
}

Department of Chemistry, Faculty of Sciences, University of Guilan, P.O. Box 41335-1914, Rasht, Iran.

Tel.:+981333367262 and fax: +981333367262 


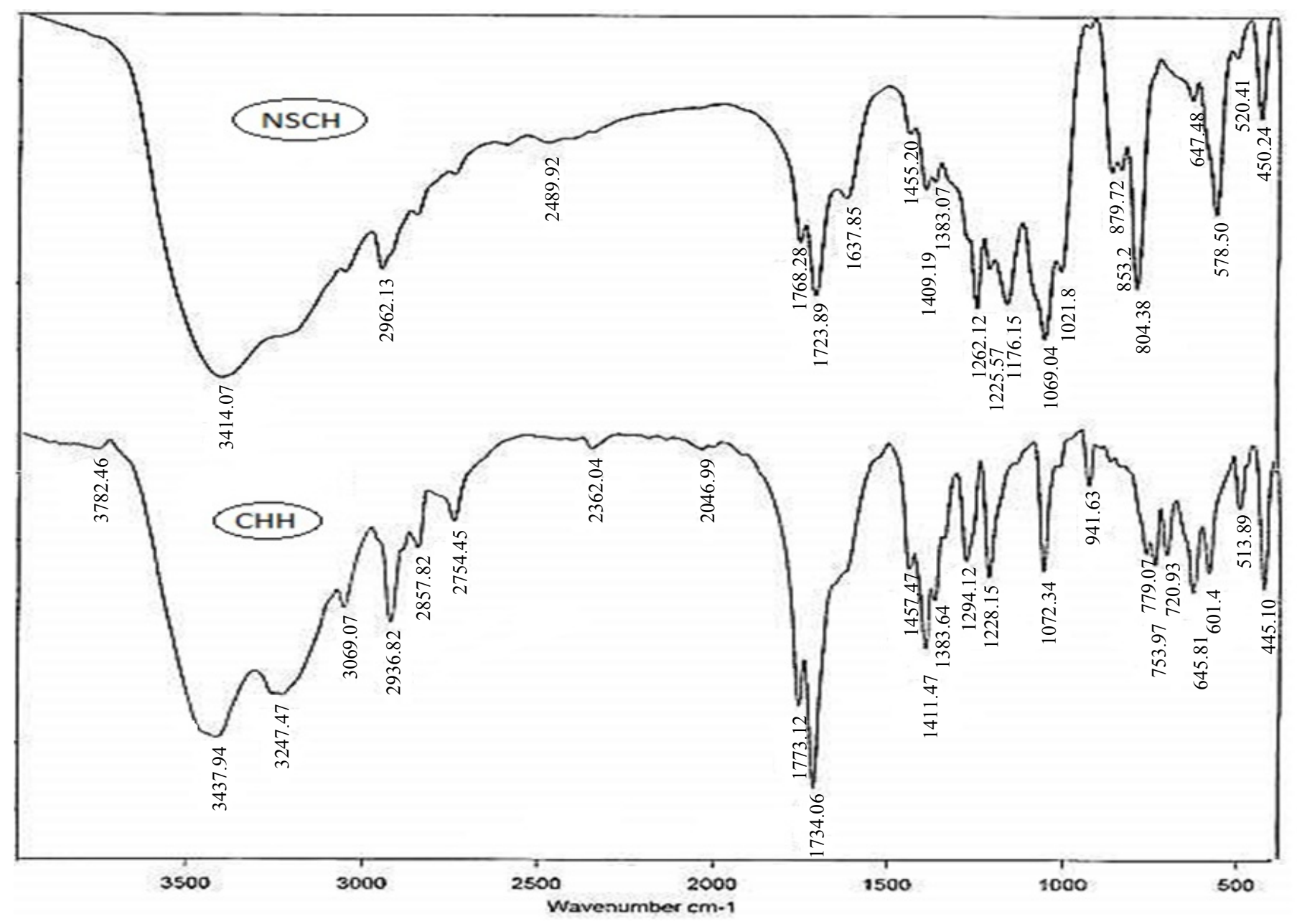

Figure SI1 FT-IR spectra of CHH and NSCH. 


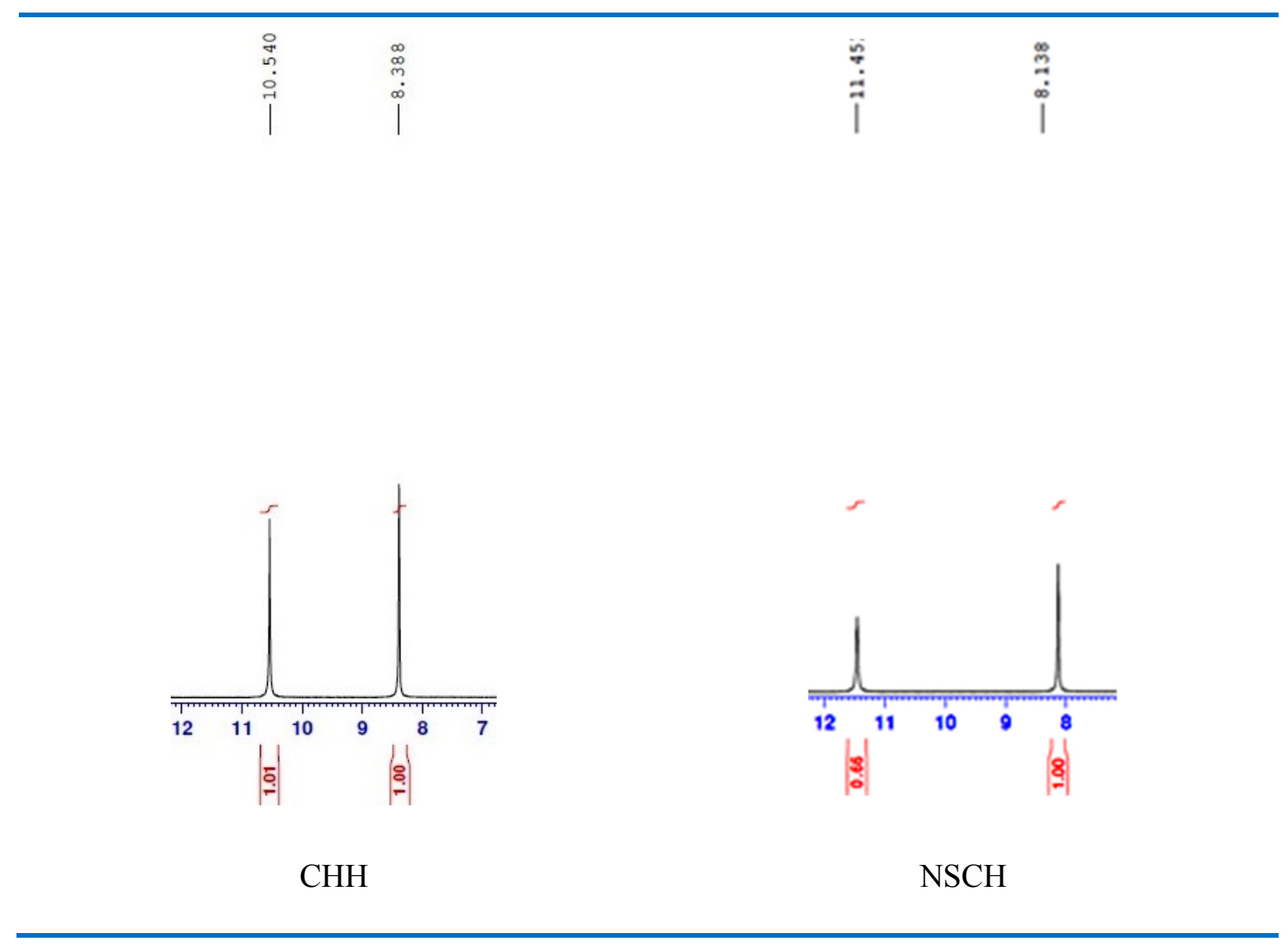

Figure SI2 ${ }^{1} \mathrm{H}$ NMR spectra of CHH and NSCH (from 7-12 ppm only). 

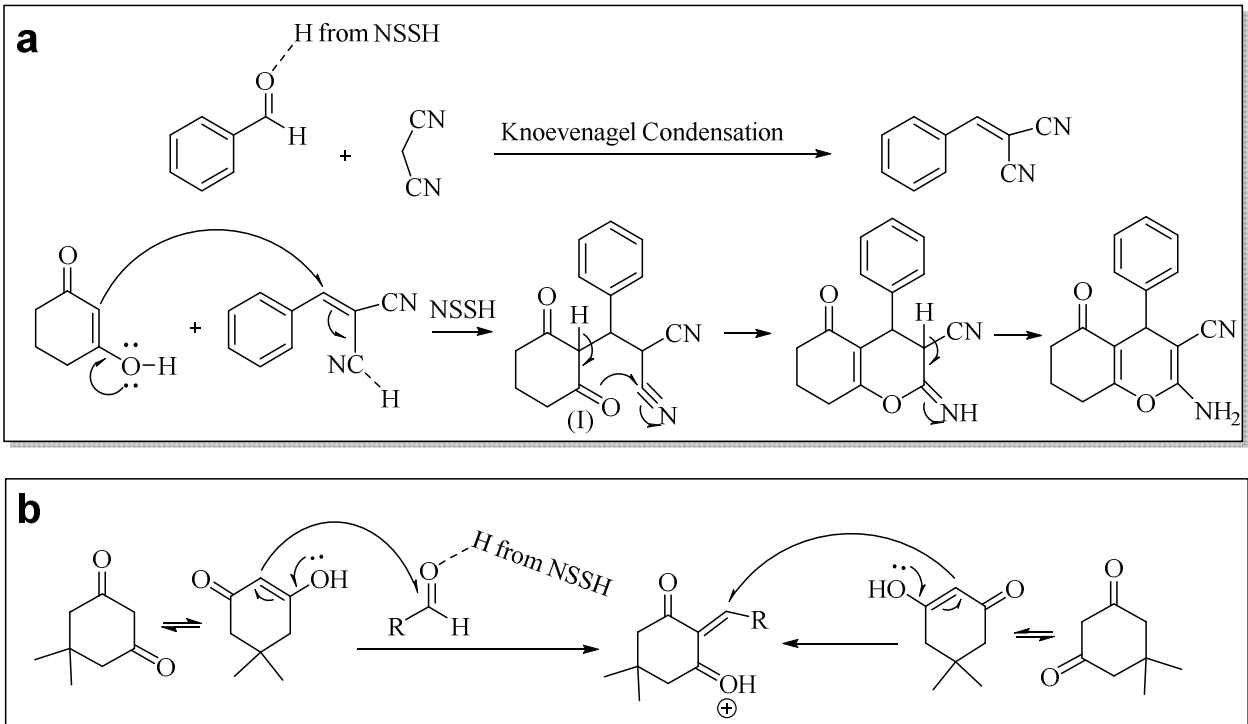

(II)

$\mathrm{NSSH}+$
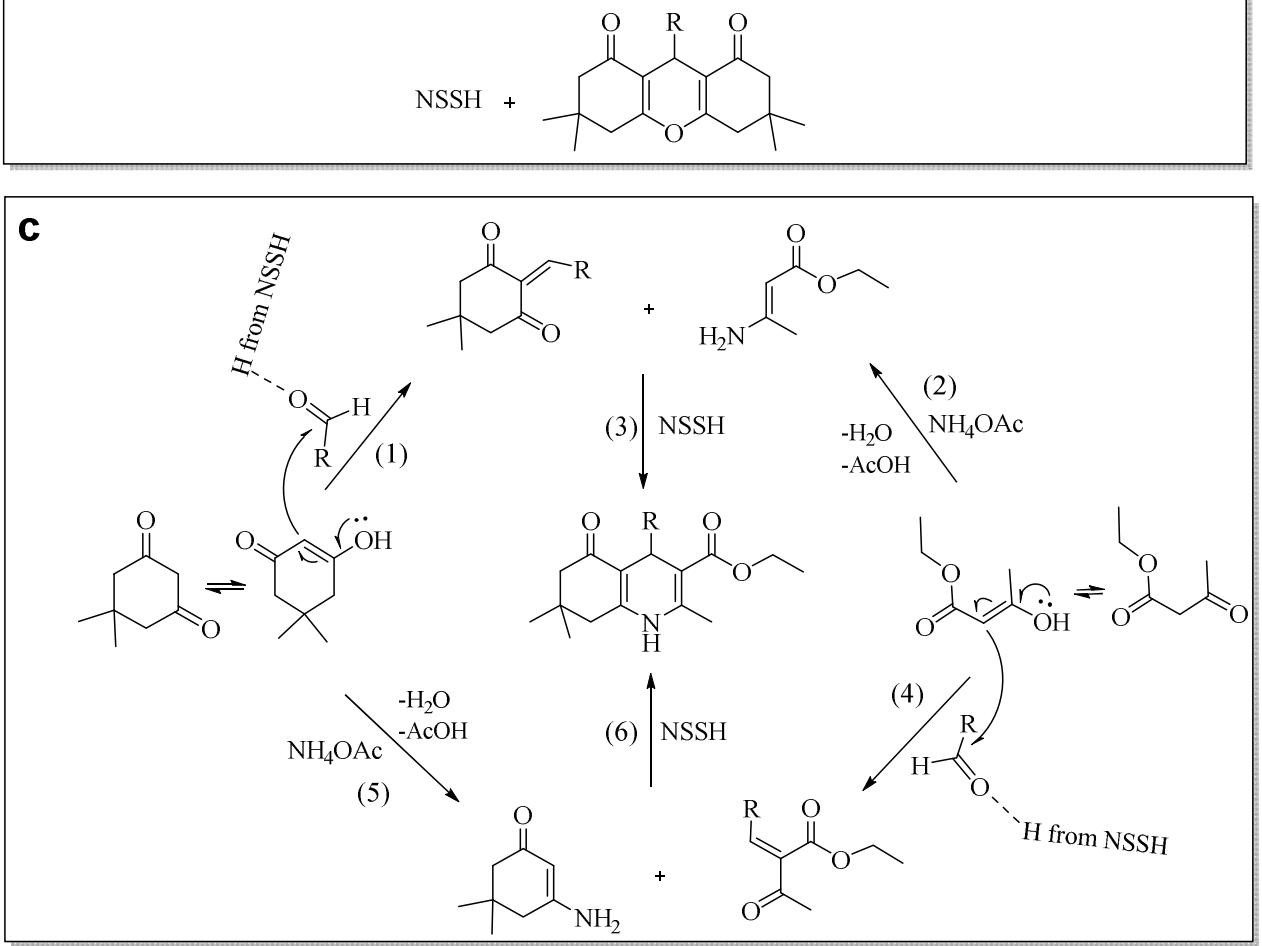

Figure SI3 Proposed mechanisms for the synthesis of tetrahydrochromene (a), 1,8dioxooctahydroxanthene (b) and hydroquinoline (c) derivatives in the presence of NSCH. 